\title{
The Framework of Urbanization with Low Living Cost: A Future Model Based on Cost Perspective
}

\author{
Zhentao Ma \\ School of Politics and Public Administration, Anyang Normal University, Anyang, China \\ Email: 3157011@163.com
}

How to cite this paper: Ma, Z. T. (2020). The Framework of Urbanization with Low Living Cost: A Future Model Based on Cost Perspective. Current Urban Studies, 8, 645-657.

https://doi.org/10.4236/cus.2020.84035

Received: November 30, 2020

Accepted: December 19, 2020

Published: December 22, 2020

Copyright $\odot 2020$ by author(s) and Scientific Research Publishing Inc. This work is licensed under the Creative Commons Attribution International License (CC BY 4.0).

http://creativecommons.org/licenses/by/4.0/

\section{(c) (i) Open Access}

\begin{abstract}
China's urbanization is generally considered to be a low-cost mode. The price distortion of land, labor, capital and other factors is the main manifestation and crux of low-cost urbanization, which successfully avoided the common problems such as large-scale urban poverty, unemployment and slums in the process of development, but also contributed to the inefficiency of urban expansion and the inequity of dualistic structure. With the advancement of urbanization, the production and living costs of big cities continue to be high, which contributes to the increase of people's survival and living costs. Based on Rawls' "Curtain of Ignorance" justice concept, this paper argues that attention should be paid to the low-income groups who are in a disadvantaged position in society based on the bottom line thinking, focusing on the underpinning function of public policy, to build a low living cost urbanization model designed to benefit the people, and truly achieve "co-construction, sharing and benefiting".
\end{abstract}

\section{Keywords}

Urbanization, Low Living Cost Mode, The Veil of Ignorance

\section{Introduction}

Cities are the greatest invention and the best hope of human beings, and the future of cities will determine the future of human beings (Glaeser, 2012). No matter whether it is pastoral capitalism, new urbanism or landscape urbanism, it is an indisputable fact that more and more people around the world will leave the countryside and go to the city. The urban population is projected to increase to 6.2 billion by 2050 in world. The urbanization rate increased from $52 \%$ in 
2011 to $66 \%$. The biggest advantage of urbanization is to reduce transaction costs, improve the frequency and efficiency of factor flowing, and make economic activities more active. The degree of participation and civilization of society are constantly improving. However, this state is based on the increasing of the whole society costs, and the cost-sharing of the state, enterprises and society is ultimately based on the improvement of individual labor value and labor productivity. If the change of labor productivity in society does not match the speed of urbanization, the employment of transferred labor force and the improvement of consumption capacity, social problems such as urban diseases will arise and fall into the "middle income trap".

China's urbanization is generally considered to be a low-cost mode, and the price distortion of land, labor, capital and other factors is the main manifestation and crux of low-cost urbanization. So, what will urbanization look like in the future with cost perspective? New urbanization in China emphasizes people-centered, aiming to correct the existing factors and institutional distortions, which inevitably makes the cost of urbanization expensive. How to solve the cost dilemma of urbanization of transferring labor force is not only a technical problem, but also a choice of urbanization development mode. Considering the impact of innovative development and the differences in the quality, structure and distribution of agricultural transfer labor force, it makes sense of thinking to problem solution of high cost in the process of urbanization, under the influence of Rawls's justice concept of "curtain of ignorance".

In order to analyze the urban cost more clearly, a cost-based urbanization model is proposed, and the structure of essay is as follows: firstly, making reflection of the existing urbanization development model; secondly, proposing the urbanization model of low living cost; thirdly, analyzing the principle of low living cost urbanization. The last part is the conclusion.

\section{Reflection of the Urbanization Development Model}

In some grand planning and research, there are many modes of urbanization development. Typically, China's National New Urbanization Plan defines the new urbanization road of "people-oriented, synchronization of four modernization, optimization of layout, ecological civilization, cultural heritage"; China National Research Center and the World Bank (2014) proposed efficient, inclusive and sustainable urbanization; Qiu Baoxing (2009) proposed "C mode" which emphasizes that under the premise of insisting on development, the new urbanization mode should not only give full play to the efficient role of market mechanism, but also compensate its negative impact at low cost. These visions and ideas should be helpful to identify the future direction of urbanization, and to identify the measures for continuous improvement in detail. However, the disadvantage is that the basic linear thinking mode followed by the research is that the future development is placed under the expectation of higher economic growth, which can easily lead to the risk of insufficient prediction. Especially as a 
prerequisite for the existence of the assumption is that the agricultural transfer of labor occupation ability, population quality and structure are continuous improvement with the advance of urbanization, their ability to integrate into the city and economic development is synchronized. That is, people benefit from development automatically. In fact, combined with the argument of Thomas Piketty (2014), this balanced and coordinated development vision of "equalizing the rich and the poor" will not be automatically realized. On the contrary, it may become worse under the influence of "technical threshold" and "Matthew effect".

The direction, objectives and task requirements of the new urbanization put forward by the existing research are an ideal state, especially most follows linear thinking, putting the future model in the context of higher expected growth rate of economic development, and easy to underestimate the difficulties. Putting the analysis in the realistic situation and combining with the realistic dilemma of shifting gears and structural adjustment in China's development, it is not difficult to find that some existing research and policy proposals in China mostly utilitilty, pay attention to the short-term but neglect the long-term, the vision designed is too ideal and abstract, and the scale they are based on is mostly" entering the city". Less consideration is given to the plight of more than 200 million migrant workers who are often in the most disadvantaged position in society. The perception and judgment of cost-benefit is the most direct and profound, which is the farthest from welfare distribution and the closest to crisis transfer. Therefore, it is necessary to make up for these neglected "bad scenarios" by means of some practical research methods, whether from the perspective of early warning or striving for the right to speak for the adaptation and integration of vulnerable groups into urbanization.

\section{Proposing the Urbanization Model of Low Living Cost}

Different groups in the city have different expectations for the city. Practice in developed countries shows that low-income groups are more concerned about whether there are opportunities to improve their situation in cities, urban prices and children's educational conditions; The middle classes, non-citizen businessmen and professionals, and visitors and tourists have different needs (see Table 1). From the perspective of public policy, the key objective of urbanization is to meet the demands of low-income groups, especially the poor groups, to integrate into urbanization. For them, the city is a place to settle down and meet the basic right of survival and life. With the rapid progress of urbanization, most of the new urban population in China comes from the rural areas lacking of original accumulation, and they are at most "semi-poor" or just out of poverty, and they are also the vulnerable groups that need to be paid attention to in the process of urbanization.

Taking cost as the core element of research, analyzing each sub-cost in detail, correcting distorted cost, increasing the cost that should not be ignored, and 
Table 1. Analysis of different social groups on different common needs of the city.

\begin{tabular}{|c|c|c|}
\hline Interest Group & Urban functions related to themselves & Main focus on cities \\
\hline $\begin{array}{l}\text { Poverty } \\
\text { Stratum }\end{array}$ & $\begin{array}{l}\text { Although life is difficult, it is better than } \\
\text { the countryside in comparison; Able to } \\
\text { save money to buy land and secure a } \\
\text { better future for their children through } \\
\text { formal education }\end{array}$ & $\begin{array}{l}\text { Income opportunities, affordable prices, } \\
\text { educational opportunities, housing and } \\
\text { transportation }\end{array}$ \\
\hline $\begin{array}{l}\text { Rich and } \\
\text { semi-rich class }\end{array}$ & $\begin{array}{l}\text { Cities are the ideal place to live, which } \\
\text { means better services, easy access to } \\
\text { business and government, and a gateway } \\
\text { to the outside world }\end{array}$ & $\begin{array}{l}\text { Social status, income, security, cheap } \\
\text { labor, attention to the quality of life and } \\
\text { the balance of quality and price of goods } \\
\text { and services }\end{array}$ \\
\hline $\begin{array}{l}\text { Non-citizen } \\
\text { business and } \\
\text { professional }\end{array}$ & $\begin{array}{l}\text { Cities are the place to get higher in a } \\
\text { short period of time, the ideal place to } \\
\text { enter the headquarters of various } \\
\text { companies and institutions, and the } \\
\text { place to spend less but enjoy decent } \\
\text { activities }\end{array}$ & $\begin{array}{l}\text { Political and social stability, security, } \\
\text { urban services, schooling, housing, } \\
\text { socialization and the labour market. } \\
\text { Focus on service availability and } \\
\text { reliability, product quality, not price }\end{array}$ \\
\hline $\begin{array}{l}\text { Visitor and } \\
\text { tourist }\end{array}$ & $\begin{array}{l}\text { The atmosphere of the city, the relaxed } \\
\text { and pleasant environment, the good } \\
\text { shopping environment, and all the } \\
\text { factors that guarantee the comfort and } \\
\text { pleasure of holidays and short term }\end{array}$ & $\begin{array}{l}\text { Availability of accommodation, } \\
\text { transportation, safety, comfort, shopping } \\
\text { environment, sightseeing resources and } \\
\text { special goods and services }\end{array}$ \\
\hline
\end{tabular}

Source: Yin Jizuo (2003) World City and Innovative City: Theory and Practice in Western Countries Shanghai: Publishing House of Shanghai Academy of Social Sciences. 38-39.

reducing the cost of excessive expenditure can provide some reference for guiding new urbanization. Under this assumption, the study synthesizes Rawls's "veil of ignorance" concept of justice, Jeremy Rifkin's (2014) prediction of "Zero Marginal Cost Society" and Qiu Baoxing's "C Mode" theory, we try to propose and develop a new model-low living cost urbanization mode, in order to solve the problems of the middle and low income groups effectively from the perspective of cost.

The low living cost urbanization mode is committed to reducing the cost of production, life, settlement and development of the people who are in a disadvantageous position in society with the perspective of cost, with the transfer of labor force as the main body, reducing non-consumption expenditure, improving cost payment ability, and alleviating the pressure of people's survival. With the help of the optimization of factor composition and the adjustment of system construction, the urbanization development model with people as the core and co-construction and sharing can be realized. The characteristics of this model are to base on the bottom line thinking, pay attention to the bottom function of public policy, to ensure the integration of low-income groups into cities and towns as a starting point, and strive to reduce the threshold, reduce loss and improve quality. It pays attention to efficiency and fairness, making urbanization an endogenous, inclusive and virtuous circle of self-organization system.

The purpose of the low living cost urbanization mode is to reshape the value concept, reduce the loss of intermediate transactions, the total social cost, and 
realize the urbanization of human beings. The most intuitive manifestation of "low cost living" is low price, low system cost, low expenditure on housing, education, health care and social security, perfect and cheap supply of public services, urban governance model devoted to promoting social harmony, reducing social conflicts, ensure efficient and clean government operation and administration system, this is a huge pattern design.

\section{The Principle of Low Living Cost Urbanization}

The low living cost urbanization model is a tentative idea and vision. This model is not a castle in the air, nor a "utopia" based on fantasy, but a key measure to adhere to the "bottom line" thinking and deal with the "low cost, unsustainable" drawbacks of traditional urbanization. It is a positive response to the high cost of urbanization in the context of full cost. It is also a useful exploration to serve the new people-oriented urbanization. Combining with the judgment of this trend, we believe that the construction of urbanization mode with low living cost must follow the principles of subject responsibility sharing, endogenous virtuous circle, two-way flow of factors, maximum individual welfare and multi-mechanism coordination on the premise of giving full play to the decisive role of the market.

\subsection{The Main Responsibility Is Shared}

It is a basic right to ensure the basic survival and development rights of low-income people in cities and towns. As we know, the peasants and the vast group of migrant workers who are bound by urbanization, occupy less social resources, low income level and weak ability to resist risks. The need for survival at least includes the physiological level and security level in Maslow's hierarchy of needs theory. With the progress of the times, some development needs have been included in the basic survival needs. The low living cost is mainly the cost of food, clothing, housing, transportation, health and education. The satisfaction of these basic conditions requires the "full cost" to be shared by all parties.

In order to cope with the problem of weak individual, including Taiwan, Japan and other regions and countries, there are ideas and practices of group heating. For example, the protection of professional farmers, on the one hand, protects the safety of domestic agricultural industry and the interests of farmers through strict restrictive measures; On the other hand, with the help of "peasant associations" and other modes, we can realize the protection of rights and interests and cooperation. In the process of promoting the urbanization model of low living cost, we should also clarify this concept, let more subjects participate in it in an organized way, assuming responsibilities and form a joint force; With the help of the whole society, the cost of the low-income class can be reduced, so that the existing cost of individuals can be transferred to social organizations or other subjects.

Under the guidance of this thought, the urbanization of low living cost must first be a multi-party sharing mode, which is based on clearly delineating the 
boundaries of individual, enterprise, government and social responsibilities, and building an appropriate structure of functional positioning and role coordination. The government, the market and the society should perform their respective duties to jointly reduce the transaction costs and institutional costs in the process of urbanization and improve the efficiency of resource allocation. On this basis, we must also consider how to give clear expectations and confidence to the rural migrant labor force, so that the cost will not be too much passed on to the vulnerable groups, and try to reduce transaction costs such as intermediate consumption.

\subsection{Endogenous Virtuous Circle}

In the field of urban planning, urban marketing model and endogenous development model are the two main development model of concern (Friedmann, 2004). The former believes that the driving force of urban development is not controlled by the city itself, but is exogenous and highly competitive; The latter classifies this model as a zero-sum game. "It will bring only small short-term material benefits and large long-term costs. The prospect of achieving sustainable development is slim" (Liu, 2011) (see Table 2). Therefore, urban development should emphasize endogeneity and realize endogenous virtuous circle. Reflecting on the process of urbanization in China, administrative dominance has become an important source of low cost and rapid expansion. While the phenomenon of land expropriation and relocation has greatly improved the urbanization rate.

It has also produced the fact that a large number of people are difficult to integrate into cities and towns and fall into a dilemma. Some typical urbanization promotion modes have failed to achieve endogenous cycle and made their sustainability weakening. For example, the export-oriented Guangdong mode; the Wenzhou mode and Suzhou mode, which rely on the external market and serve the traditional trade, processing and manufacturing, are flourishing for a while, but they are gradually fading with the transformation of China's economy.

Table 2. Two models of urban development.

\begin{tabular}{ccc}
\hline & $\begin{array}{c}\text { Mode I: City Marketing } \\
\text { (Based on external } \\
\text { developments) }\end{array}$ & $\begin{array}{c}\text { Model II: Endogenous Urban } \\
\text { Development (Based on internal } \\
\text { developments) }\end{array}$ \\
\hline Action Space & Core City & City-region \\
Time frame & Long Term Liabilities & Short-term liabilities \\
Scope of influence & Maximization of economic growth & $\begin{array}{c}\text { Optimization of many development } \\
\text { goals }\end{array}$ \\
Pattern & Exogeny & Endogenous \\
Sustainability & Competitive (zero-sum) & Cooperative networks (organizations) \\
\hline
\end{tabular}

Source: John Friedmann. Planning Global Cities: An Endogenous Development Model. Urban Planning Forum. 2004(4): 3 . 
Urbanization influenced by external markets such as administrative dominance or export reling on administrative allocation of resources and "flexible and positive response" to cooperate with exogenous forces such as transnational and cross-regional capital, which under the pressure of the end of the export-oriented economic model and the continuous rise of labor costs, the economic development and urban transformation of these regions are confronted. The urbanization level and quality improvement has been greatly slowed down. The singleness of urban economy, the incompleteness of urban function and structure make the urban system too weak and the development capacity too fragile, which contributes to the systemic risk of the city, increases the inherent cost of the city and makes it more and more unsustainable.

In theory, there are two ways for regional development: regional wealth creation and inter-city trade, and they must be kept roughly balanced (Thomas et al., 2000). A series of cases of urban decay show that "city-region" can not rely entirely on external forces to obtain sustainable development. The construction of low living cost urbanization mode must be based on endogenous power, and constantly realize the cycle of "variable change $\rightarrow$ trigger demand $\rightarrow$ meet demand $\rightarrow$ take place economic behavior $\rightarrow$ produce economic benefits $\rightarrow$ invest in other industries $\rightarrow$ realize social benefits $\rightarrow$ touch the variable change again", and enhance the virtuous circle ability of urban politics, economy, culture and resource allocation. To form such an endogenous cycle, the most basic thing is to have a solid industrial support capacity. A relatively complete industrial and planning system that can provide employment opportunities and achieve sustainable development.

Urban changes in history reveal the impact of "resource curse" on the transformation. For most cities in transformation and development in China, the system construction of industrial base, the optimization and renewal of industrial structure, and the extension and upgrading of industrial chain are the basis for the city to maintain its sustainable attraction. Detroit, a city in the United States, and many resource-exhausted cities in China, as typical cases of transformation failure, have proved the importance of solid industrial support capacity and continuous creation of new jobs to absorb foreign population and maintain the urban system. The enlightenment of urbanization model with low living cost is that urban operators should have strategic vision and prediction ability, take enhancing endogenous development power as the starting point, adjust and update timely through scientific planning system, and intensify efforts in industrial transformation, social transformation, cultural development and institutional guarantee. It will lay a solid foundation for the realization of low living cost urbanization and sustainable urban development.

\subsection{Two-Way Flow of Factor}

Urbanization with low living cost is no longer a one-way flow of factors from rural areas to cities, but a two-way interaction and "convection" of factors be- 
tween urban and rural areas. Under the traditional urban-rural dual system, the focus of industry and city-oriented policy deviates from the policy, which makes the urban-rural factor flow in a "one-way" state for a long time, and the rural population, resources and funds continue to gather in the city, but the reverse flow is almost blocked. According to statistics, China's rural public investment is far lower than the city, and the gap is very large. Rural public investment is only $39 \%$ of the city, and the transfer payment of rural social assistance is only $8.9 \%$ of the city (Wei, 2015). This one-way flow of factors leads to the widening gap between urban and rural development, which not only increases the scarcity of urban resources and competitive pressure, but also raises the price of factors. On the other hand, the migration of urban population to rural areas, the extension of urban public resources, and the coverage of urban public services are still at a very low level. In fact, with the development of urbanization and the promotion of urban-rural integration, many developed areas have the conditions and basis for the two-way flow of urban-rural elements, and it is necessary to explore first. In addition, from the perspective of cost-benefit, on the one hand, putting rural factor resources in the market environment can restore their due value and give rural migrant labor force the initial capital to leave the countryside and take root in the city; On the other hand, two-way flow can also alleviate urban pressure, break the closed space of "only entering and not leaving" in cities and towns, and play the role of "pressure relief valve". So that the urban system becomes more open, inclusive and in a virtuous circle of normal metabolism.

Of course, the realization of two-way flow is a complex project due to the basic and fundamental nature of factor resources. Especially, on the premise of unclear property rights of rural factor resources, it is easy to fall into the predicament of unstable foundation and the reform can only stay on the surface if we seek a breakthrough in superstructure at the beginning. Another worth discussing issue is whether urban residents should be allowed to settle in rural areas according to their own wishes in the future, even under the reform of rural property rights system. The allocation of factors will eventually achieve regional convergence in price, that is, the allocation of factors in urban and rural areas will reach an optimal equilibrium model. The driving force that dominates the switch between urban and rural areas will no longer be the trade-off between cost and benefit: the transfer of rural residents to cities is no longer simply for the improvement of urban infrastructure, high quality, full coverage of public services; When urban residents return to the countryside, they are no longer striving for a "share" from collective land, but on the basis of value recognition and lifestyle choice. The mode dominated by market and will become the mainstream of factor flow and the goal of two-way factor flow.

\subsection{Maximum Individual Welfare}

City size is an important variable that determines the cost of a city and affects the total social welfare. The social welfare problem of urbanization is mostly 
based on the discussion of urban scale. Arnott \& Stiglitz (1979) studies the optimal city size, believes that the optimal city size should be the population size that maximizes social welfare or per capita social welfare. Moreover, the larger the city scale, the higher the product output efficiency, the more obvious the advantage of high labor productivity caused by agglomeration effect, the more jobs created, types of public services provided, and the stronger the attraction and population gathering ability of the city. On the other hand, the existence of "siphon effect" not only provides factor support for big cities and mega-cities, but also erodes the development capacity of small and medium-sized cities and towns. Moreover, the scale expansion and vicious circle caused by expansion of cities have become the root of "urban disease". The "organic evacuation" road proposed by the field of urban planning once led the planning of "Greater London" and "Greater Paris" after World War II, and most of the world's cities have experienced the process of population dispersal. This shows that the expansion of cities is not infinite, and their scale has a critical value of zero marginal revenue.

Examining the traditional urbanization path, we can also find that the natural conduction of agglomeration effect is a continuous, inertial and irregular process (Yang et al., 2014). Therefore, it is difficult to interpret the problem of floating population in cities from the perspective of "economic man". One of the profound variables comes from expected returns, not immediate returns. Different towns between the income are not uniform, and can be called the welfare of the space-time division; it is this division promote the imbalance of urbanization and spatial distribution of disorder. The failure of the decision-making of "small towns, big strategies" in China shows that the urbanization model of administrative dominance and multi-blossom can not achieve the intention of the policy. The local "urban disease" of the first-tier cities such as Beijing Shanghai also confirms the old planning system and structural layout, which can not support the over-centralized mega-city and mega-city model, both of which have caused some damage to individual welfare. For example, the population guidance of Beijing and other mega-cities has made a large number of people at the bottom lose the opportunity to maintain employment in big cities.

The urbanization mode of low living cost should take the individual welfare as the starting point, not only pay attention to the accumulation effect, but also consider the centralized cost. Moreover, with the technological progress and the improvement of social labor productivity, the optimal scale is also in constant change. The previous "small town" strategy or the optimal city size calculated by some scholars has not success in practice. Therefore, we should abandon the previous linear thinking of city scale, take the principle of maximizing individual welfare, start from the protection of human rights, especially the rights of the bottom people, and define the city scale and development progress according to local conditions in different regions and stages. The ideal urbanization mode with the greatest individual social welfare is also the mode with the best scale 
economy, intensive spatial layout and the most beneficial residents. One misunderstanding is that a large influx of population will inevitably dilute the existing welfare of the city and deviate from the original intention of maximizing welfare.

In fact, many mega-cities with "urban disease" have not been rooted in the large number of people, but in the lack of forward-looking planning and design, and the lack of timely industrial transformation. Admittedly, the "morbid" urbanization surrounded by traffic congestion, environmental pollution and frequent social problems is not an ideal model, but on the premise that economies of scale are not optimal, this cannot be a reason to restrict population from entering big cities. The urban development at home and abroad shows that "urban disease" is the old road that developed countries have gone through, and also the stage that developing countries must go through. The root cause of all urban problems is the stage of development, not the mode of development. Adhering to the principle of maximizing individual welfare, many restrictive measures for big cities and mega-cities, especially in the process of controlling urban population, should be re-examined to maximize the exclusion and expulsion of "outsiders" at the bottom of society.

\subsection{Multi-Party Mechanism Synergy}

Urbanization is a process of self-adjustment, but the self-adjustment of cities is not completely spontaneous. From the perspective of system theory, urban is composed of various elements, many subsystems, complex structure, interaction and mutual evolution, which together constitute an organism. Usually, the evolution of urban system has two ways: market-led and government-led. The cities developed by natural agglomeration under the influence of the market belong to the self-organization growth, that is, the "bottom-up" model, while the cities constructed under the leadership of the government develop from the "top-down" model. Urbanization in western countries is mostly a spontaneous self-organization model, which forms a complex system of automatic debugging and coupling within urbanization. With the help of local governments, China's urbanization has joined some exogenous factors, and the renewal of institutional mechanisms can not be automatically completed, but needs dual drive of competition and coordination. The role of competition does not need much elaboration. Synergy is the interaction of various decentralized effects in the combination makes the total effect better than the sum of individual effects (Zheng \& Liang, 2006), that is, through the synergy between the main bodies of the system, we can achieve the effect of " $1+1>2$ " which is difficult alonely. Traditional administrative management, social management services and a series of institutional mechanisms serving the transformation of urban and rural development models, due to the lag of change and the lack of anticipation of new situations and problems, the "fragmentation" of departments and main functions leads to the difficulty of mechanism coordination, and the overall function is greater than that of individuals. It has increased the cost and difficulty of urbanization. 
The strategy of urbanization with low living cost should adhere to the strategy of coordinated development and orderly promotion. Among them, coordinated development includes interconnection, urban-rural coordination, inter-city coordination, regional coordination, ecological environment protection coordination and five-flow coordination of material flow, energy flow, information flow, currency flow and talent flow; At the same time, we should realize the equalization of public services and eliminate the dual structure, and ultimately achieve common prosperity (Niu, 2015). These synergies can not be achieved completely by spontaneous, nor can they be solved by administrative leadership, but need to play a role rely on the institutional leverage behind. Therefore, the synergy mechanism is particularly important. Coordinated development is becoming the basic strategy of new urbanization, and to achieve coordinated development, we must build a multi-party coordination mechanism, which is also the institutional basis for the realization of low living cost, urbanization model. Realizing the integration of urban and rural areas is the ultimate goal of the coordinated development mechanism in urbanization.

The push-pull model put forward by Donald Borg and others in the late 1950s, is one of the most influential theories in the study of urban and rural floating population. In fact, China's cities and towns, from the perspective of market allocation of resources, are a pulling force, but the addition of urban-rural dual system variables, especially considering China's household registration system, has become a strong internal resistance, thus making this theoretical explanation invalid. In the system design, management system and construction planning of traditional urbanization, urban and rural areas are artificially separated and policies are formulated separately. Institutional barriers have become the biggest obstacle to urbanization. The urbanization model of low living cost aims to break this institutional barrier, consider urban and rural areas as a whole, implement the policy of coordination between urban and rural areas, so that rural factor resources can obtain the same qualifications and treatment as urban factor resources, and solve the structural contradictions of regional differences, rich and poor differences, and urban-rural differences. At the same time, we should achieve a balanced and homogeneous basic public service system between urban and rural areas, regions and different occupational groups; effective coordination of new urban management system, governance mechanism and administrative system; through the construction of multi-mechanism, we can create a beneficial, harmonious production space, living space, ecological space, social space and spiritual space for the people to meet the needs of different levels.

Government have responsibility to design mechanism and system. In China, a country with strong administrative control of resources and elements, serving the large-scale, large-span and highly complex urbanization process, the government still needs to play a guiding role, dare to break free from the "fence" of vested interests, from the dependence on "land finance", from the management 
mode of "short, flat and fast" high-pressure management and control, comply with the requirements of people-oriented, comprehensive, coordinated and sustainable development, with the help of system adjustment, clarify the specific functions in the process of urbanization, and do a good job in planning, system design, public service, environmental protection, market supervision, social management and other work. With the help of the coordination of multi-mechanism, we can balance the interests of all aspects of the game and realize the urbanization of people-oriented, multi-party coordination and market promotion.

\section{Main Conclusions}

China's urbanization is generally considered to be a low-cost unsustainable mode. Synthesizing Rawls's "veil of ignorance" concept of justice, prediction of "Zero Marginal Cost Society" and "C Mode" theory, the study should try to propose and develop a new model to effectively solve the problems of the middle and low income groups from the perspective of cost.

The urbanization mode of low living cost is different from the welfare society in North Europe, and also different from the completely spontaneous mode in free market economy. It is a starting point to protect the middle and low income groups, to reduce the threshold of urbanization, to improve the quality of urbanization, and to focus on both efficiency and fairness.

We believe that this mode is the choice to deal with social and livelihood issues, to cross the "middle income trap", to correct the distorted allocation of factors, to alleviate the pressure of resources and environment, and to build a coordinated and shared society; following the principles of multi-subject responsibility sharing, endogenous virtuous circle, two-way flow of elements, maximum individual welfare and muti-mechanism coordination. By using planning to restrict the mode and behavior of urbanization with low living cost, we must recognize the drawbacks of traditional planning system, and strictly restrict the behavior of urbanization with low cost from the concept of urban-rural integration, the requirement of large planning and the concept of mufti-conformity, so as to make urbanization a spontaneous and gradual mode.

\section{Conflicts of Interest}

The author declares no conflicts of interest regarding the publication of this paper.

\section{References}

Arnott, R. J., \& Stiglitz, J. E. (1979). Aggregate Land Rents, Expenditure on Public Goods, and Optimal City Size. Quarterly Journal of Economics, 93, 471-500. https://doi.org/10.2307/1884466

Development Research Center of the State Council, World Bank (2014). China Promotes Efficient, Inclusive and Sustainable Urbanization. Beijing: China Development Press. 
Friedmann, J. (2004). Planning Global Cities: An Endogenous Development Model. Urban Planning Forum, No. 4, 3-7.

Glaeser, E. (2012). Victory of the City (pp. 1-2). Shanghai: Shanghai Academy of Social Sciences Press.

Liu, Y. L. (2011). Doubt about the Optimal City Size in China. Urban Planning, No. 5, 76-81.

Niu, W. Y. (2015). The Success of the City Is the Success of the Country. http://www.zgcsj.net/NewShow/375.shtml

Piketty, T. (2014). Capital in the Twenty-First Century. Beijing: CITIC Press. https://doi.org/10.4159/9780674369542

Qiu, B. X. (2009). Differentiation of Urbanization Model with Chinese Characteristics "C Model": Surpassing the Temptation of "A Model" and the Quagmire of "B Model". Urban Development Research, No. 1, 15-26.

Rifkin, J. (2014). Zero Marginal Cost Society. Beijing: CITIC Publishing House.

Thomas, V. et al. (2000). The Quality of Growth. Oxford, New York: Oxford University Press.

Wei, H. K. (2015). Annual Meeting of the China Urban 100 Forum. http://www.china.com.cn/zhibo/2015-10/17/content_36826624.htm

Yang, L.-J., Yang, Y.-C., \& Wang, L.-C. (2014). Study on Competition and Coordination Mechanism in Urban System. Human Geography, No. 6, 104-108.

Yin, J. Z. (2003). World City and Innovative City: Theory and Practice in Western Countries (pp. 38-39). Shanghai: Publishing House of Shanghai Academy of Social Sciences.

Zheng, G., \& Liang, X.-R. (2006). Overall Synergy: A Way to Subdue Innovation: A Study on Overall Synergy Mechanism of Technology and Non-Technology Elements. Research on Science of Science, No. 12, 55-62. 